\title{
Cutting Rate and Surface Characteristic Analysis in CNC Wire Electrical Discharge Machining of Aluminium Bronze
}

\author{
Savas EVRAN, Bilcen MUTLU, Mustafa KURT
}

\begin{abstract}
In this study, cutting rate and surface characteristic analysis in wire electrical discharge machining of aluminium bronze were investigated. Cutting rate analyses were performed according to Taguchi L18 $\left(2^{1 \times 3^{2}}\right)$ orthogonal array. Machining parameters such as wire type, duration between two pulses $\left(B_{T}\right)$ and pulse time $\left(A_{T}\right)$ were used as control factors. Raw data obtained for cutting rate were converted to $S / N$ ratio values. Optimum levels of the machining parameters for cutting rate were determined using analysis of signal-to-noise $(S / N)$ ratio. Significant machining parameters and their percentage contributions on results were obtained using Analysis of Variance (ANOVA). Regression analysis was performed to model the relationship between cutting rate and machining parameters. Analyses of surfaces machined of workpiece using both two wires for minimum and maximum cutting rate were observed using scanning electron microscope (SEM) and surface roughness device.
\end{abstract}

Keywords: cutting rate; Scanning Electron Microscope (SEM); surface finish; Wire Electrical Discharge Machining (WEDM)

\section{INTRODUCTION}

The EDM process called thermal erosion [1] is one of the earliest non-traditional processing operation [2] and is performed using thermo electric energy occurred in a small gap between electrode and work piece [3]. Wire electrical discharge machining (WEDM) is a different EDM type and wire tool electrode is used as cutting tool in WEDM operation. Shapes with convoluted geometries may be machined at high degree of dimensional accuracy level and good surface characteristic by using WEDM operation [4]. The available literature provides several studies wherein different performance indices are defined, such as cutting speed, surface roughness, width of kerf, dimensional accuracy, material removal rate, gap current, gap voltage, micro-hardness, heat affected zone, wire wear ratio, X-ray analysis-based characteristics and similar. Maher et al. [5] present a study including the surface roughness, cutting speed and heat affected zone in WEDM operation. They used different machining parameters such as peak current with two levels, pulse on time and wire tension with three levels based on Taguchi L18 orthogonal array. In addition, they used ANFIS modelling to determine the analysis and the average of three measurements for surface roughness, cutting speed and heat affected zone analyses was used. Shandilya et al. [6] performed an analysis for average cutting speed in WEDM operation and used four machining parameters. They used response surface methodology and artificial neural network for analysis. Galindo-Fernandez et al. [7] performed a work consisting of the machining of the pollycrystalline diamond based on WEDM operation and evaluated cutting speed and surface finish analyses. They obtained the higher cutting speed using coated wires according to uncoated hard brass wire. Also, in WEDM operations, the analysis of the surface characteristics of machined workpiece is important. Mouralova et al. [8] observed the surface morphology and topography on machined surface of the pure aluminium using various levels of the different machining parameters based on WEDM operation. Annebushan Singh and Kumar Sarma [9] investigated the surface characteristics on machined surfaces of MWCNT alumina composites based on different levels of various machining parameters in
WEDM operation. Lodhi and Agarwal [10] evaluated the surface roughness and SEM analysis of machined surface of workpieces based on WEDM operation. They used four machining parameters in operations and found peak current as most effective parameter on surface roughness. In literature, there are several works performed using different wire types. Wire types as one of the machining parameters may be important for performance measurements. Tosun and Pihtili [11] studied the influence of the processing parameters on wire crater size in WEDM operation. Kuriakose and Shunmugam [12] presented a study using zinc-coated brass wire and uncoated brass wire with $0.25 \mathrm{~mm}$ diameters according to Taguchi orthogonal array and they suggested that coated wire be preferred for uniform surface characteristics compared to uncoated wire. Kapoor et al. [13] reported the importance of the wire types such as uncoated and coated wires in WEDM operation. In this work, the effects of machining parameters such as wire type, duration between two pulses and pulse time on cutting rate in wire electrical discharge machining of aluminium bronze were carried out using L18 orthogonal array based on Taguchi method. ANOVA was performed at $95 \%$ confidence level to see meaningful machining parameters and their percent contribution on cutting rate. In addition, influences of the machining parameters on the cutting rate were investigated using regression analysis. The experiments analyzed for maximum and minimum cutting rate using brass and zinc coated brass wires were used for surface characteristic observations such as SEM and surface roughness.

\section{EXPERIMENTAL AND STATICAL PROCEDURE}

Cutting rate analyses were performed based on WEDM operation. The analyses were conducted based on Taguchi L18 $\left(2^{1} \times 3^{2}\right)$ orthogonal array. Machining parameters such as wire type, duration between two pulses and pulse time were used as control factors. First and second levels of wire type were selected as uncoated brass wire $\left(W_{U C T}\right)$ and zinc coated brass wire $\left(W_{C T}\right)$, respectively. Machining parameters and their levels were tabulated in Tab. 1. 
Table 1 Machining Parameters and their Levels

\begin{tabular}{|l|c|c|c|c|}
\hline \multicolumn{1}{|c|}{ Machining Parameters } & Unit & Level 1 & Level 2 & Level 3 \\
\hline Wire Type & - & $W_{U C T}$ & $W_{C T}$ & - \\
\hline Duration Between Two Pulses $\left(B_{T}\right)$ & $\mu \mathrm{s}$ & 4 & 6 & 8 \\
\hline Pulse Time $\left(A_{T}\right)$ & $\mu \mathrm{s}$ & 0.6 & 0.8 & 1.0 \\
\hline
\end{tabular}

Electrical discharge occurred during the pulse time whereas it did not occur in the duration between two pulses. The pulse time and the duration between two pulses in WEDM operation are illustrated in Fig. 1.

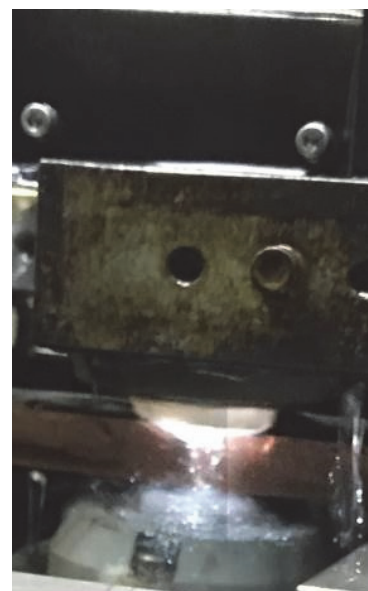

(a) Pulse time

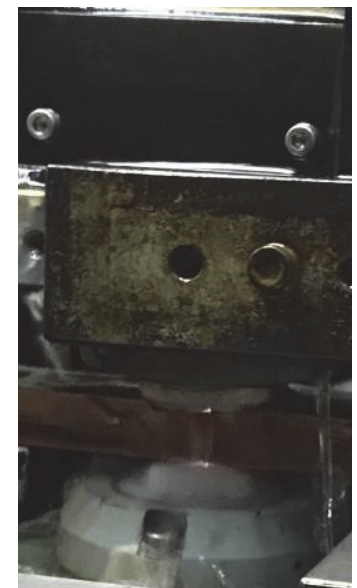

(b) Duration between two pulses
Figure 1 WEDM operation (a) pulse time and (b) duration between two pulses

Other machining parameters were maintained using machine unit $(\mathrm{mu})$ and these parameters were machine voltage $(-80 \mathrm{mu})$, ignition pulse current $(8 \mathrm{mu})$, servo control reference mean voltage $(60 \mathrm{mu})$, injection pressure setpoint $(4 \mathrm{mu})$, wire mechanical tension $(1.10 \mathrm{mu})$, maximum feed rate $(4 \mathrm{mu})$, short pulse time $(0.4 \mathrm{mu})$, and wire feed rate $(10 \mathrm{mu})$. In addition, uncoated brass wire and zinc coated brass wire of $0.25 \mathrm{~mm}$ diameters as cutting tool were used to perform the analysis. Aluminium bronze (CuAl14Fe4MnCo) was used as workpiece. Chemical composition of the workpiece [19] is tabled in Tab. 2.

Table 2 Chemical composition of Aluminium Bronze [19]
\begin{tabular}{|c|c|c|c|c|}
\hline $\mathrm{A} 1$ & $\mathrm{Fe}$ & $\mathrm{Mn}$ & Other & $\mathrm{Cu}$ \\
\hline 14.2 & 5.2 & 2.3 & Max. 0.5 & Rest \\
\hline
\end{tabular}

The raw workpiece has $250 \mathrm{~mm}$ length, $20 \mathrm{~mm}$ thickness and $30 \mathrm{~mm}$ width. The cross section base and high sizes of parts machined were $10 \mathrm{~mm}$ and $20 \mathrm{~mm}$ respectively. During the cutting time, cutting rate values were taken from machine monitor directly. The first and last $3 \mathrm{~mm}$ cutting length are not included in the measurements to obtain homogenous analysis. Scanning electron microscope (SEM) and surface finish analyses of the part surfaces machined using maximum and minimum cutting rates for two type wires were performed using JSM$7100 \mathrm{~F}$ field emission scanning electron microscope and Mitutoyo SJ-201 surface roughness tester. Cutting operations were carried out under CharmillesRobofil 510 CNC Wire EDM Machine. Raw material with clampedfree boundary condition and machined specimens are presented in Fig. 2.

In experimental analysis, the higher cutting rate was the indication of better results. Thus combination of optimum machining parameters for maximum cutting rate was carried out using larger is better (HB) quality characteristic. The quality characteristic for "Larger is better" is presented in Eq. (1) [14].

$$
(S / N)_{\mathrm{HB}} \text { for } C R=-10 \cdot \log \left(n^{-1} \sum_{i=1}^{n}\left(y_{i}^{2}\right)^{-1}\right)
$$

in which, $n$ indicates number of cutting rate analysis in a trial and $y_{i}$ expresses the ith data determined.

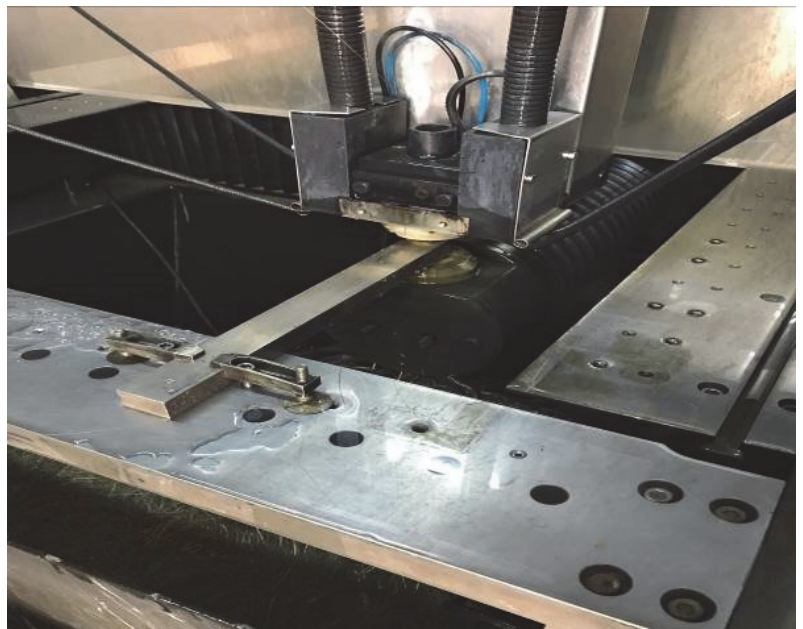

(a) Raw material for clamped free boundary condition

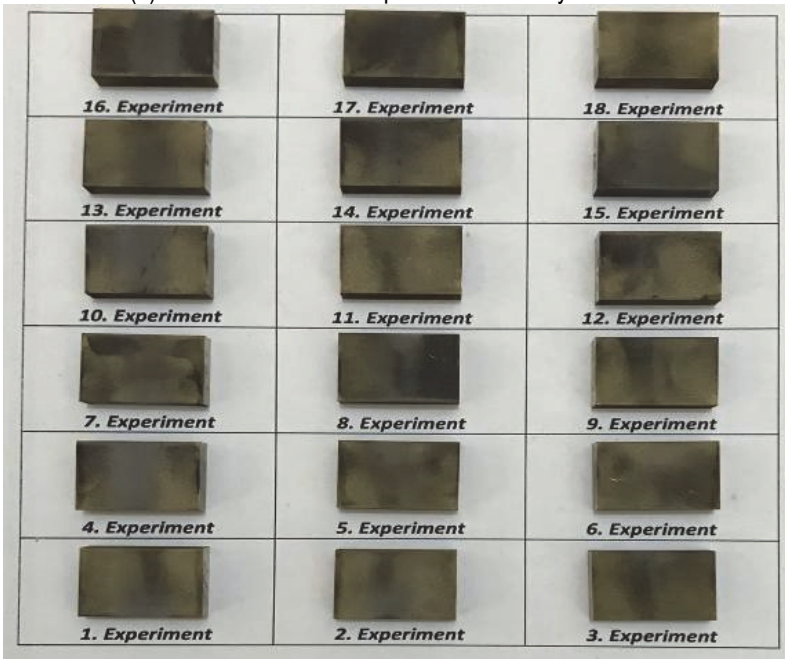

(b) Machined specimens

Figure 2 Experimental analysis: (a) raw material with clamped free boundary condition, (b) machined specimens

\section{EXPERIMENTAL RESULTS AND DISCUSSIONS}

Eighteen experiments were observed using Taguchi L18 orthogonal array to analyze the effects of the machining parameters on the cutting rate. During the cutting time, cutting rate values were taken from machine screen directly. These data and their $S / N$ ratio values are tabled in Tab. 3 .

Maximum cutting rate result in wire electrical discharge machining of aluminium bronze was obtained for the twelfth experiment as $8.25 \mathrm{~mm} / \mathrm{min}$. This situation can be explained by the melting point of the material. Poroś and Zaborski [15] reported that the cutting efficiency is higher for materials with a smaller melting point. 
Table 3 Experimental Results for Cutting Rate

\begin{tabular}{|c|c|c|c|c|c|}
\hline \multirow{2}{*}{ Test } & \multicolumn{2}{|c|}{ Machining Parameters } & \multicolumn{2}{c|}{ Results } \\
\cline { 2 - 6 } & Wire Type & $B_{T}$ & $A_{T}$ & $\begin{array}{c}\text { Cutting Rate } \\
C R(\mathrm{~mm} / \mathrm{min})\end{array}$ & $\begin{array}{c}S / N \text { Ratio } \\
\eta(\mathrm{dB})\end{array}$ \\
\hline 1 & $W_{U C T}$ & 4.0 & 0.6 & 4.60 & 13.2552 \\
\hline 2 & $W_{U C T}$ & 4.0 & 0.8 & 6.00 & 15.5630 \\
\hline 3 & $W_{U C T}$ & 4.0 & 1.0 & 7.20 & 17.1466 \\
\hline 4 & $W_{U C T}$ & 6.0 & 0.6 & 3.65 & 11.2459 \\
\hline 5 & $W_{U C T}$ & 6.0 & 0.8 & 5.00 & 13.9794 \\
\hline 6 & $W_{U C T}$ & 6.0 & 1.0 & 6.40 & 16.1236 \\
\hline 7 & $W_{U C T}$ & 8.0 & 0.6 & 2.95 & 9.3964 \\
\hline 8 & $W_{U C T}$ & 8.0 & 0.8 & 4.10 & 12.2557 \\
\hline 9 & $W_{U C T}$ & 8.0 & 1.0 & 5.50 & 14.8073 \\
\hline 10 & $W_{C T}$ & 4.0 & 0.6 & 5.40 & 14.6479 \\
\hline 11 & $W_{C T}$ & 4.0 & 0.8 & 6.85 & 16.7138 \\
\hline 12 & $W_{C T}$ & 4.0 & 1.0 & 8.25 & 18.3291 \\
\hline 13 & $W_{C T}$ & 6.0 & 0.6 & 4.50 & 13.0643 \\
\hline 14 & $W_{C T}$ & 6.0 & 0.8 & 5.75 & 15.1934 \\
\hline 15 & $W_{C T}$ & 6.0 & 1.0 & 7.35 & 17.3257 \\
\hline 16 & $W_{C T}$ & 8.0 & 0.6 & 3.80 & 11.5957 \\
\hline 17 & $W_{C T}$ & 8.0 & 0.8 & 4.90 & 13.8039 \\
\hline 18 & $W_{C T}$ & 8.0 & 1.0 & 6.40 & 16.1236 \\
\hline & Overall Mean $\left(\bar{T}_{C R}\right)$ & & 5.477 & \\
\hline & & & & \\
\hline
\end{tabular}

\subsection{Analysis of Optimum Levels and Effects of Machining} Parameters

Analyses were performed using L18 orthogonal array based on WEDM operations in order to evaluate the effects and optimum levels of machining parameters on the cutting rate. The average results and their $S / N$ ratio values based on each level of each machining parameter are given in Tab. 4.
As can be seen in Tab. 4, the optimum machining parameters for maximum cutting rate are obtained using zinc coated brass wire, duration between two pulses at first level and pulse time at third level. The $S / N$ ratio data in Tab. 4 were used to carry out the effects of the machining parameters on the cutting rate. The main effects plot of the machining parameters for $S / N$ ratio are illustrated in Fig. 3 .

\begin{tabular}{|c|c|c|c|c|c|c|}
\multicolumn{9}{c|}{ Table 4 Response Table for Cutting Rate } \\
\hline \multirow{3}{*}{ Level } & \multicolumn{3}{|c|}{$\begin{array}{c}\text { S/ Ratio } \\
(\mathrm{dB})\end{array}$} & $\begin{array}{c}\text { Means } \\
(\mathrm{mm} / \mathrm{min})\end{array}$ \\
\cline { 2 - 7 } & $\begin{array}{c}\text { Wire } \\
\text { Type }\end{array}$ & $B_{T}$ & $A_{T}$ & $\begin{array}{c}\text { Wire } \\
\text { Type }\end{array}$ & $B_{T}$ & $A_{T}$ \\
\hline 1 & 13.750 & 15.940 & 12.200 & 5.044 & 6.383 & 4.150 \\
\hline 2 & 15.200 & 14.490 & 14.580 & 5.911 & 5.442 & 5.433 \\
\hline 3 & - & 13.000 & 16.640 & - & 4.608 & 6.850 \\
\hline Delta & 1.450 & 2.950 & 4.440 & 0.867 & 1.775 & 2.700 \\
\hline Rank & 3 & 2 & 1 & 3 & 2 & 1 \\
\hline
\end{tabular}

Fig. 3 shows that the cutting rate obtained using zinc coated brass wire is higher than uncoated brass wire. In literature, a study [16] shows that cutting speed obtained using high-speed brass wire is smaller than zinc-coated brass wire. The study [16] can support the results obtained. In another study, Kapoor et al. [13] reported that the zinccoated wire in WEDM provides the highest efficiency with faster cutting speed. In addition, the increasing of the duration between two pulses decreases the cutting rate whereas the increasing of pulse time increases the cutting rate. This situation is in agreement with [17].

Machining Parameters
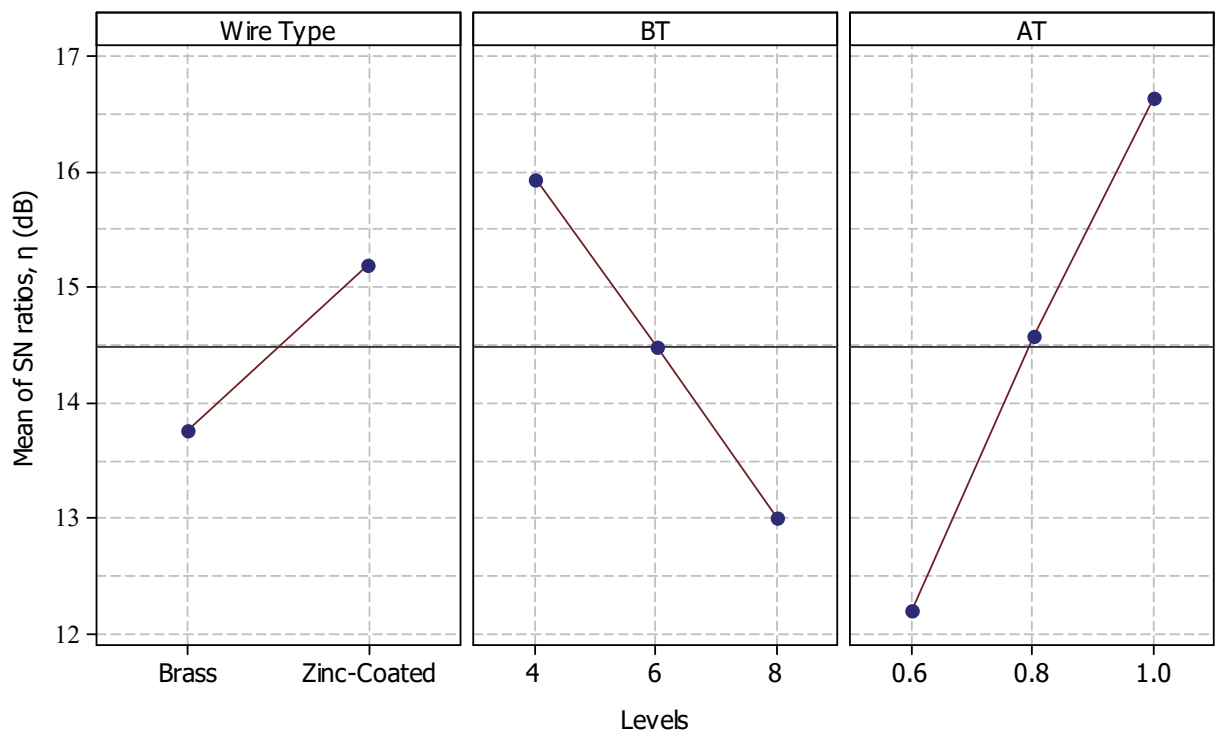

Signal-to-noise: Higher is better

Figure 3 Main influences plot for $S / N$ ratios of machining parameters

\subsection{Analysis of Variance for Cutting Rate}

Analysis of Variance (ANOVA) was observed to determine important machining parameters and their percentage contribution on the cutting rate. ANOVA at 95\% confidence level was performed using raw data for cutting rate values. The results obtained for $R-S q=$ $99.73 \%$ and $R-S q(\operatorname{adj})=99.61 \%$ are tabulated in Tab. 5 .
Table 5 ANOVA results for cutting rate

\begin{tabular}{|c|c|c|c|c|c|c|}
\hline Source & $D F$ & Seq SS & Variance & $F$ & $P$ & $\%$ Cont. \\
\hline Wire Type & 1 & 3.3800 & 3.3800 & 428.20 & \multirow{3}{*}{0} & 9.71 \\
\hline$\overline{B_{T}}$ & 2 & 9.4636 & 4.7318 & 599.45 & & 27.17 \\
\hline$A_{T}$ & 2 & 21.8878 & 10.9439 & 1386.44 & & 62.85 \\
\hline Error & 12 & 0.0947 & 0.0079 & & & 0.27 \\
\hline Total & 17 & 34.8261 & & & & \\
\hline
\end{tabular}

ANOVA results show that wire type, duration between two pulses and pulse time are significant machining parameters on the cutting rate according to $P<0.05$ value. 
In addition, most effective machining parameters on the cutting rate were found to be $A_{\mathrm{T}}$ with $62.85 \%$ contribution, $B_{\mathrm{T}}$ with $27.17 \%$ contribution and Wire Type with $9.71 \%$ contribution, respectively.

\subsection{Estimation of Optimized Result for Cutting Rate}

The optimum result of the cutting rate was determined using the optimum levels of the significant machining parameters. These data are given in Tab. 4 and it was found as second level of wire type (zinc coated brass wire), first level of duration between two pulses and third level of pulse time. The estimation mean of cutting rate can be calculated using Eq. (2) [14]

$\bar{\mu}_{C R}=\bar{W}_{C T}+\bar{B}_{T 1}+\bar{A}_{T 3}-2 \bar{T}_{C R}$

where, $\bar{T}_{C R}=5.477$ is overall mean based on L18 orthogonal array. Zinc coated brass wire $\bar{W}_{C T}$ was selected as second level of wire type and is taken as 5.911 for calculations. $\bar{B}_{T 1}$ and $\bar{A}_{T 3}$ refer to duration between two pulses at first level and pulse time at third level and are taken as 6.383 and 6.850 from Tab. 4, respectively. According to Eq. (2), $\bar{\mu}_{C R}$ is calculated as $8.19 \mathrm{~mm} / \mathrm{min}$. The confidence interval $(C I)$ of the predicted data for the confirmation experiment (CE) of cutting rate can be determined using Eq. (3) [14].

$C I_{\mathrm{CE}}=\left(F_{\alpha ; 1 ; f_{e}} V_{e r}\left[\frac{1}{\eta_{e f f}}+\frac{1}{R}\right]\right)^{0.5}$

in which, $F_{\alpha ; 1 ; f_{e}}$ indicates the $F$ value for $95 \%$ confidence. $f_{e}$ denotes the degree of freedom for error and is taken as 12 from Tab. 5. Thus $F=4.7472$ is found based on $F$ ratio listed [18] at $95 \%$ confidence $(\alpha=0.05) . V_{e r}$ indicates the error value of variance is taken as 0.0079 from Tab. 5. $R$ is sample size according to confirmation experiment and is taken as 4. Effective number of replications for cutting rate $\left(\eta_{\text {eff }}\right)$ is calculated using Eq. (4) [14].

$\eta_{\text {eff }}=\frac{N}{1+T_{\mathrm{DF}}}$

where, $N$ is total number of experiments for cutting rate used as $72(18 \times 4)$. Total value for degree of freedom $\left(T_{\mathrm{DF}}\right)$ for significant machining parameters is determined as 5 and so $\eta_{\text {eff }}$ is calculated as 12 . In addition, $C I_{\mathrm{CE}}$ is found as 0.112 and the predicted optimum result of cutting rate based on $95 \%$ CI is determined as [14],
$\bar{\mu}_{C R}-C I_{\mathrm{CE}}<\mu_{C R}<\bar{\mu}_{C R}+C I_{\mathrm{CE}}$

The predicted and experimental results obtained using optimum levels of machining parameters based on $95 \%$ confidence are given in Tab. 6 .

Table 6 Predicted and experimental results

\begin{tabular}{|c|c|c|c|}
\hline $\begin{array}{c}\text { Optimum } \\
\text { Machining } \\
\text { Parameters }\end{array}$ & $\begin{array}{c}\text { Predicted } \\
\text { Results } \\
(\mathrm{mm} / \mathrm{min})\end{array}$ & $\begin{array}{c}\text { Experimental } \\
\text { Results } \\
(\mathrm{mm} / \mathrm{min})\end{array}$ & $\begin{array}{c}\text { Predicted Confidence } \\
\text { Intervals at } 95 \% \\
\text { Confidence Level }\end{array}$ \\
\hline$W_{C T} B_{T 1} A_{T 3}$ & 8.19 & 8.25 & $8.078<\mu_{C R}<8.302$ \\
\hline
\end{tabular}

\subsection{Regression Analysis for Cutting Rate}

Regression analysis was carried out using raw data for cutting rate to see the influences of machining parameters on the cutting rate. All machining parameters were included in Equation 6 since $\mathrm{p}$ value was smaller than 0.05 value for $95 \%$ confidence level. The regression equation obtained for $R-S q=99.6 \%$ and $R-S q(\operatorname{adj})=99.6 \%$ using Minitab R15 software was expressed as follows:

$C R=3.25+0.867\left(W_{T}\right)-0.888\left(B_{T}\right)+1.35\left(A_{T}\right)$

According to the regression analysis, wire type and pulse time have positive effects on the cutting rate whereas duration between two pulses has negative effects.

\subsection{Surface Characteristic Analysis}

Surface characteristic analysis was carried out using machined surfaces of workpieces for minimum and maximum cutting rate according to L18 orthogonal array in Tab. 3. Minimum and maximum cutting rate obtained using uncoated brass wire was found for experiment 7 and 3, respectively. Experiment 7 was performed using first level of the pulse time and third level of the duration between two pulses whereas experiment 3 was carried out using third level of the pulse time and first level of the duration between two pulses. In addition, minimum and maximum cutting rate performed using zinc coated brass wire were detected for experiment 16 and 12, respectively. Sixteenth experiment was performed using the pulse time at first level and the duration between two pulses at third level whereas twelfth experiment was carried out using the pulse time at third level and the duration between two pulses at first level. Thus four samples were selected for surface characteristic observation based on SEM and surface finish. Surface finish analysis of machined surfaces was measured by Mitutoyosurftest SJ-201 device (99.6\% accuracy) and measuring length (cut-off-length) was used as $0.8 \mathrm{~mm}$. The surface roughness $(R a)$ was performed based on six various measurements. The surface roughness results obtained are tabulated in Tab. 7.

Table 7 Surface Roughness Results

\begin{tabular}{|l|c|c|c|c|c|c|c|}
\hline \multirow{2}{*}{ Experiments } & \multicolumn{5}{c|}{ Surface Roughness, $R a(\mu \mathrm{m})$} \\
\cline { 2 - 8 } & $R a 1$ & $R a 2$ & $R a 3$ & $R a 4$ & $R a 5$ & $R a 6$ & Average $R a$ \\
\hline Third Experiment & 3.252 & 3.239 & 3.116 & 3.203 & 3.256 & 3.301 \\
\hline Seventh Experiment & 2.674 & 2.705 & 2.579 & 2.619 & 2.602 & 2.582 & 3.228 \\
\hline Twelfth Experiment & 2.994 & 2.929 & 3.168 & 3.089 & 3.051 & 3.104 & 2.627 \\
\hline Sixteenth Experiment & 2.192 & 2.112 & 2.210 & 2.219 & 2.231 & 2.196 & 3.056 \\
\hline
\end{tabular}


Tab. 7 shows that surface roughness results analyzed using uncoated brass wire are higher than the surface roughness values determined using zinc coated brass wire. In literature, a study [16] shows that surface roughness obtained using zinc coated brass wire is lower according to high speed brass wire. This study [16] can support the results obtained. In addition, pulse time produces positive effects on the increasing of the surface roughness whereas duration between two pulses performs negative effects. In other words, the increasing of the pulse time and the decreasing of the duration between two pulses increase the surface roughness. These findings are in agreement with a study [17]. In addition, the results obtained were supported with SEM analysis. SEM analysis of surfaces machined of experiments in Tab. 7 was performed using JSM-7100F field emission scanning electron microscope based on an accelerating voltage of $20.0 \mathrm{kV}$ and the images were observed at $1000 \times$ magnification. The SEM micrographs of machined surfaces are illustrated in Fig. 4.

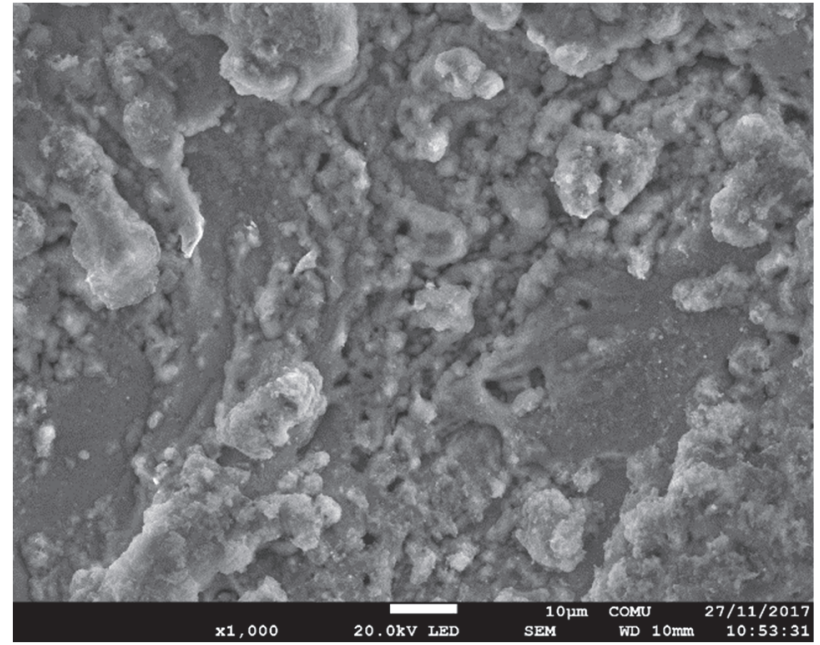

(a) Third Experiment

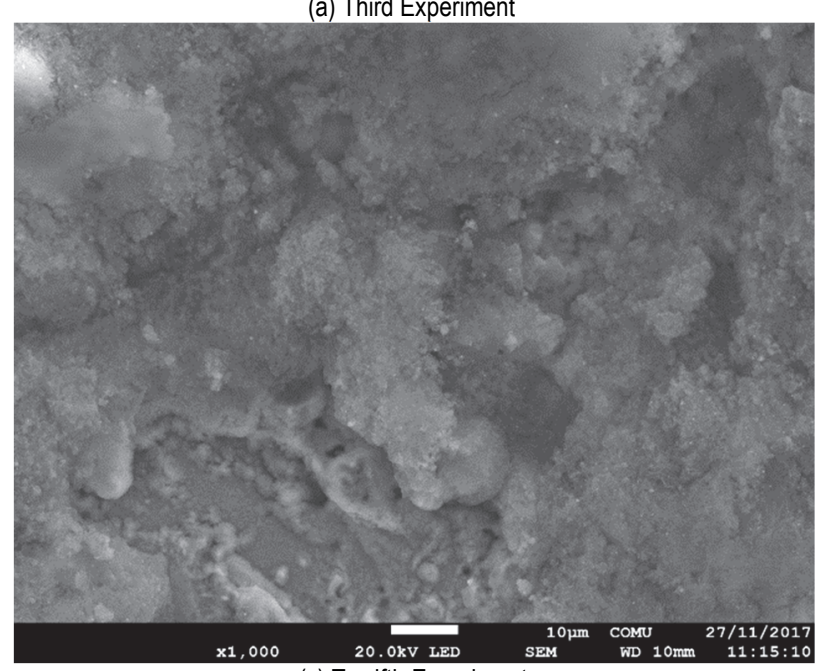

(c) Twelfth Experiment

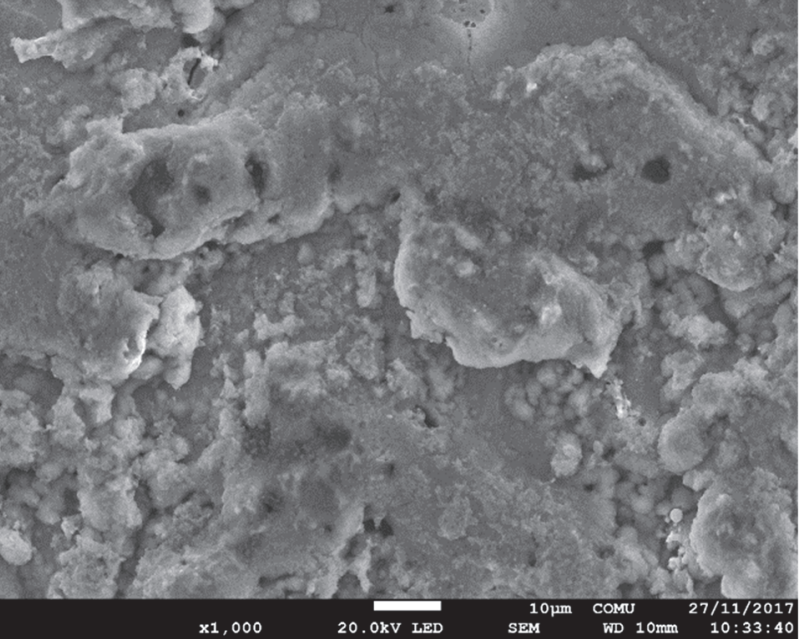

(b) Seventh Experiment

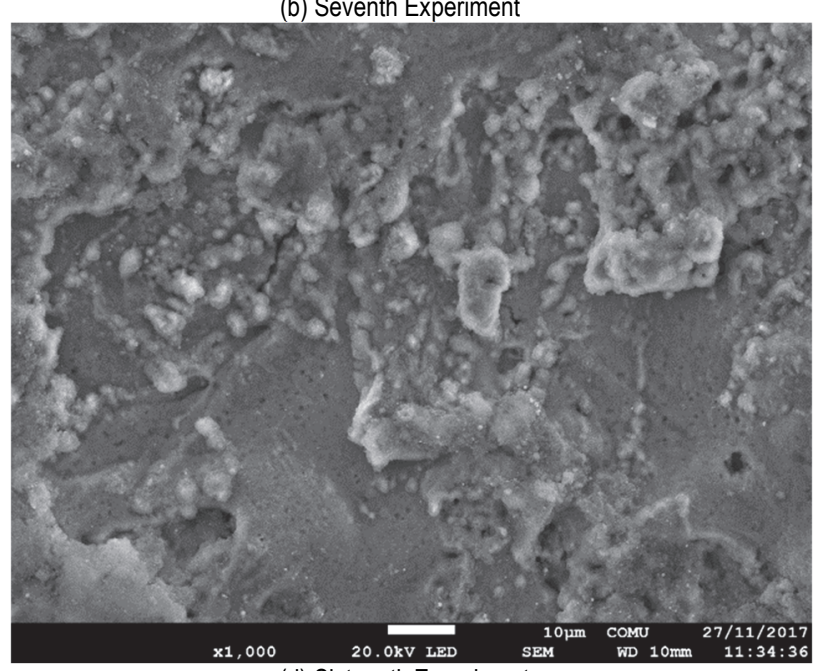

(d) Sixteenth Experiment

Figure 4 SEM micrographs: (a) Third experiment, (b) Seventh experiment, (c) Twelfth experiment, and (d) Sixteenth experiment

Fig. 4 shows that different type holes, slag and cracks can be formed on wire EDM surfaces. The formations such as holes, slag and cracks can cause an increase in surface roughness. These holes are more obvious on surfaces based on the third and seventh experiments. This situation can be explained using wire types. The highest hole formations, which occur per unit of surface area for four experiments are found for third experiment. Slag formations are more obvious on surfaces with twelfth and sixteenth experiments. Although the same wire is used in the twelfth and sixteenth experiments, maximum slag formations are obtained for twelfth experiment. This situation can be explained using different levels of machining parameters such as the pulse time and the duration between two pulses. The high pulse time and low duration between two pulses were used in the twelfth experiment. The increasing of the pulse time increases the slag formation.

\section{CONCLUSION}

In this study, cutting rate and surface characteristic analysis in wire electrical discharge machining of aluminium bronze were investigated using different machining parameters such as wire type, duration between two pulses $\left(B_{T}\right)$ and pulse time $\left(A_{T}\right)$. Workpiece surfaces machined using both two wires for minimum and maximum cutting rate were carried out using scanning electron microscope (SEM). In addition, surface finish analysis of these surfaces was investigated using surface roughness tester. The following conclusions can be revealed according to evaluated study: 
1) Cutting rate obtained using zinc coated brass wire is bigger than uncoated brass wire.

2) The increasing of pulse time increases the cutting rate whereas duration between two pulses decreases.

3) Optimum machining parameters are carried out using zinc coated brass wire, first level of duration between two pulses and third level of pulse time.

4) According to $p$ value at $95 \%$ confidence level, wire type, duration between two pulses and pulse time are significant machining parameters on the cutting rate.

5) The most effective machining parameters on the cutting rate are determined as pulse time with $62.85 \%$ contribution, duration between two pulses with $27.17 \%$ contribution and wire type with $9.71 \%$ contribution respectively.

6) The predicted optimum value of cutting rate is calculated as $8.078<\mu_{C R}<8.302$ in $\mathrm{mm} / \mathrm{min}$.

7) Surface roughness values obtained using zinc coated brass wire are lower than surface roughness performed using brass wire.

8) Pulse time has positive effects on the increasing of the surface roughness whereas duration between two pulses performs negative effects.

9) According to regression analysis, the wire type and pulse time have positive influences on the cutting rate whereas duration between two pulses has negative influences.

10) The increasing of the pulse time increases the slag and holes formations.

11) SEM analysis shows that machined surfaces of the workpieces have holes, slag and crack formations.

12) The increasing of the cutting rate for both two wires increases the surface roughness.

\section{REFERENCES}

[1] Muthuramalingam, T. \& Mohan, B. (2015). A review on influence of electrical process parameters in EDM process. Archives of Civil and Mechanical Engineering, 15(1), 87-94. https://doi.org/10.1016/j.acme.2014.02.009

[2] Chakraborty, S., Dey, V., \& Ghosh, S. K. (2015). A review on the use of dielectric fluids and their effects in electrical discharge machining characteristics. Precision Engineering, 401-406. https://doi.org/10.1016/j.precisioneng.2014.11.003

[3] Abbas, M. N., Solomon, D. G., \& Bahari, F. M. (2007). A review on current research trends in electrical discharge machining (EDM). International Journal of Machine Tools and Manufacture, 47(7-8), 1214-1228. https://doi.org/10.1016/j.ijmachtools.2006.08.026

[4] Kapoor, J., Singh, S., \& Khamba, J. S. (2012). Highperformance wire electrodes for wire electrical-discharge machining - a review. Proc. Inst. Mech. Eng. Part B-J. Eng. Manuf., 226(A11), 1757-1773. https://doi.org/ 10.1177/0954405412460354

[5] Maher, I., Sarhan, A. A. D., Barzani, M. M, \& Hamdi, M. (2015). Increasing the productivity of the wire-cut electrical discharge machine associated with sustainable production. Journal of Cleaner Production, 108(Part A), 247-255. https://doi.org/10.1016/j.jclepro.2015.06.047

[6] Shandilya, P., Jain, P. K., \& Jain, N. K. (2013). RSM and ANN modeling approaches for predicting average cutting speed during WEDM of SiCp/6061 Al MMC. Procedia Engineering, 64(Supplement C), 767-774. https://doi.org/10.1016/j.proeng.2013.09.152

[7] Galindo-Fernandez, M., Diver, C., \& Leahy, W. (2016). The prediction of surface finish and cutting speed for wire electro-discharge machining of polycrystalline diamond. Procedia CIRP, 42(Supplement C), 297-304. https://doi.org/10.1016/j.procir.2016.02.289

[8] Mouralova, K., Kovar, J., Klakurkova, L., Bednar, J., Benes, L., \& Zahradnicek, R. (2018). Analysis of surface morphology and topography of pure aluminium machined using WEDM. Measurement, 114(Supplement C), 169-176. https://doi.org/10.1016/j.measurement.2017.09.040

[9] Singh M. A. \& Sarma. D. K. (2018). Parametric and subsurface analysis of MWCNT alumina composites in WEDM process. Ceramics International, 44(2), 2186-2197. https://doi.org/10.1016/j.ceramint.2017.10.174

[10] Lodhi, B. K. \& Agarwal, S. (2014). Optimization of machining parameters in WEDM of AISI D3 steel using Taguchi Technique. Procedia CIRP, 14(Supplement C), 194-199. https://doi.org/10.1016/j.procir.2014.03.080

[11] Tosun, N. \& Pihtili, H. (2003). The effect of cutting parameters on wire crater sizes in wire EDM. The International Journal of Advanced Manufacturing Technology, 21(10), 857-865. https://doi.org/10.1007/s00170-002-1404-1

[12] Kuriakose, S. \& Shunmugam, M. (2004). Characteristics of wire-electro discharge machined Ti6Al4V surface. Materials Letters, 58(17), 2231-2237. https://doi.org/10.1016/..matlet.2004.01.037

[13] Kapoor, J., Singh, S., \& Khamba, J. S. (2010) Recent developments in wire electrodes for high performance WEDM. Proceedings of the world congress on engineering, 2, 1-4.

[14] Ross, P. J. (1996). Taguchi techniques for quality engineering loss function, orthogonalexperiments, parameter and tolerance design, McGraw-Hill International Editions, $2^{\text {nd }}$ Edition, New York, USA.

[15] Poroś, D. \& Zaborski, S. (2009). Semi-empirical model of efficiency of wire electrical discharge machining of hard-tomachine materials. Journal of Materials Processing Technology, 209(3), 1247-1253. https://doi.org/10.1016/j.jmatprotec.2008.03.046

[16] Nourbakhsh, F., Rajurkar, K. P., Malshe, A. P., \& Cao, J. (2013). Wire electro-discharge machining of titanium alloy. Procedia CIRP, 513-18. https://doi.org/10.1016/j.procir.2013.01.003

[17] Kuriakose, S., Mohan, K., \&Shunmugam, M. S. (2003). Data mining applied to wire-EDM process. Journal of Materials Processing Technology, 142(1), 182-189. https://doi.org/10.1016/S0924-0136(03)00596-X

[18] Roy, R. K. (1990). A primer on the Taguchi Method, Dearborn, Michigan, Society of Manufacturing Engineers.

[19] Saglam Metal, (2017) http://www.saglammetal.com/tr/urundetay/bronz/aluminyum-bronzlari/cupral-10-aluminyumbronz.

\section{Contact information:}

\section{Savas EVRAN,}

(Corresponding author)

Department of Machine and Metal Technologies,

Vocational School of Canakkale Technical Sciences,

Canakkale Onsekiz Mart University, 17020 Canakkale, Turkey

sevran@comu.edu.tr

\section{Bilcen MUTLU,}

Department of Mechanical Engineering,

Faculty of Technology, Marmara University, 34722 Kadıköy - İstanbul, Turkey bmutlu@marmara.edu.tr

\section{Mustafa KURT,}

Department of Mechanical Engineering,

Faculty of Technology, Marmara University, 34722 Kadıköy - İstanbul, Turkey mkurt@marmara.edu.tr 